Original Article

\title{
Using Machine Intelligence to Uncover Alzheimer's Disease Progression Heterogeneity
}

\author{
Bessi Qorri ${ }^{1 \dagger}$, Mike Tsay ${ }^{2}$, Abhishek Agrawal ${ }^{3}$, Rhoda Au ${ }^{4}$, and Joseph \\ Geraci $^{2,5+*}$ \\ ${ }^{1}$ Department of Biomedical and Molecular Sciences, Queen's University, Kingston \\ ON, Canada \\ ${ }^{2}$ NetraMark Corp, Toronto, ON, Canada \\ ${ }^{3}$ Novartis, Director Oncology USA, Advisor to the Gates Foundation \\ ${ }^{4}$ Department of Anatomy \& Neurobiology, Neurology and Epidemiology, Boston \\ University Schools of Medicine and Public Health, Boston, MA, USA \\ ${ }^{5}$ Department of Pathology and Molecular Medicine, Queen's University, Kingston, \\ ON, Canada
}

†First authorship

${ }^{*}$ Correspondence: Joseph Geraci, Department of Pathology and Molecular Medicine, Queen's University, Kingston, ON, Canada; NetraMark Corp, Toronto, ON, Canada; geracij@queensu.ca

ORCID \# Joseph Geraci: 0000-0003-0967-2164

\begin{abstract}
Aim: Research suggests that Alzheimer's disease (AD) is heterogeneous with numerous subtypes. Several existing and proprietary machine learning frameworks were applied to transcriptomic data. Through a proprietary interactive machine learning system, we were able to uncover several underlying biological mechanisms associated with AD pathology. These results, in turn, informed new hypotheses and identified novel targets for treatment. This paper reviews how the use of explainable machine learning technologies that are capable of extracting insights from small data can potentially provide a new taxonomy of disease. This is an introduction to


emerging analytic efforts that can more precisely elucidate the heterogeneity of AD. We share results from such an effort involving a set of AD subject transcriptomic samples where we provide a combinatorial view of how the pathology associated with what we call AD could emerge.

Methods: A public AD data set (GSE84422) consisting of transcriptomic data of postmortem brain samples from healthy controls $(n=121)$ and $A D(n=380)$ subjects was analyzed. Data were processed by an artificial intelligence platform designed to discover potential drug repurposing candidates and then by an interactive augmented intelligence program.

\section{Results:}

Using perspective analytics, we identified six perspective classes: Class I is defined by $T U B B 1, A S B 4$, and PDE5A; Class II by $N R G 2$ and ZNF3; Class III by IGF1, $A S B 4$, and GTSE1; Class IV is defined by cDNA FLJ39269, ITGA1, and CPM; Class $\mathrm{V}$ is defined by PDE5A, PSEN1, and NDUFS8; Class VI is defined by DCAF17, cDNA FLJ75819, and SLC33A1. We hypothesize that these classes represent biological mechanisms that may act alone or in any combination in order to manifest an Alzheimer's pathology.

Conclusions: Using a limited transcriptomic public database, six different classes that drive $\mathrm{AD}$ were uncovered, supporting the premise that $\mathrm{AD}$ is a heterogeneously complex disorder. The perspective classes each highlighted genetic pathways associated with vasculogenesis, cellular signaling and differentiation, metabolic function, mitochondrial function, nitric oxide, and metal ion metabolism. These results are not exhaustive but demonstrate that even within a relatively small study sample, next-generation machine intelligence is capable of uncovering multiple genetically driven subtypes. These six classes represent various ways that one may manifest dementia, Alzheimer's subtypes, or preclinical cognitive aging. The interplay among these genetic factors reveals a more profound underlying complexity of AD that may be responsible for the confluence of several biological factors. The models and the underlying hypotheses generated using novel analytic methods may translate 
into potential treatment pathways.

\section{Keywords}

Alzheimer's disease, machine learning, genetic subtypes, disease heterogeneity, drug repurposing, augmented intelligence, machine intelligence, artificial intelligence, target discovery

\section{Introduction}

Alzheimer's disease (AD) is the most common form of dementia, contributing to 60$70 \%$ of cases [1]. This neurodegenerative disease is characterized by neuronal cell damage and concomitant cognitive and functional decline, predominantly affecting older individuals, with two-third being women, and prevalence expected to continue to rise as the population ages [2-4]. There is currently no definitive cure to prevent or attenuate the progression of this debilitating disease. Research efforts aimed at disease modification have focused on the amyloid and tau pathways - the significant contributors of $\mathrm{AD}$ pathology, due to excessive deposition of $\beta$-amyloid $(\mathrm{A} \beta)$ peptides and hyperphosphorylated tau proteins contributing to DNA and RNA damage [5-7]. However, of the current clinically approved AD drugs, none are disease-modifying therapies (DMTs), and instead, broadly target AD symptoms [8]. Despite over 100 agents in the current $\mathrm{AD}$ treatment pipeline, the last $\mathrm{AD}$ drug approved by the U.S. Food and Drug Administration (FDA) was memantine, an N-methyl-D-aspartate (NMDA) receptor AD antagonist, in 2003 [9, 10]. While the Chinese FDA recently approved the clinical use of oligomannate (GV-971), international drug trials are underway to confirm results and validate use outside of China (NCT03715114, NCT02986529, NCT02293915) [11]. Due to gaps in our understanding of AD etiology and the complex interactions between genomic and environmental factors that lead to disease heterogeneity, a multimodal approach towards precision medicine is necessary. 
There are currently very few consistently reported susceptible risk loci associated with AD. Early-onset AD (EOAD), which follows a Mendelian inheritance pattern, is primarily associated with mutations in one of three genes - amyloid precursor protein (APP), presenilin-1 (PSEN1), and presenilin-2 (PSEN2) [12]. However, late-onset AD (LOAD) accounts for over $95 \%$ of $\mathrm{AD}$ cases and is associated with a more complex genomic makeup. To date, apolipoprotein E $(A P O E)$, a lipid carrier involved in cholesterol metabolism, is the strongest genetic risk factor for LOAD. Specifically, the $A P O E \& 4$ allele has been reported to have a lower affinity for lipoproteins and poorly binds $A \beta$ [13]. Genome-wide association studies (GWAS) have identified several other susceptibility loci that confer AD risk to varying degrees that can be broadly categorized into those involved in immunity, lipid homeostasis, cytoskeletal interactions, endocytosis, and apoptosis [8, 14-16].

Machine learning (ML) efforts allow for a more systems-level approach that takes into account complex genetic interactions to reveal critical insights into disease etiology and assist with the identification of new drug targets [17]. While there has been extensive research using ML models to classify AD risk, discriminate between $\mathrm{AD}$ and mild cognitive impairment (MCI), and predict MCI-to-AD conversion based on structural and functional magnetic resonance imaging (MRI), positron emission tomography (PET) scans, and cerebrospinal fluid (CSF), there is less known about genetic subtypes within the AD patient population [18-21]. A recent study revealed sex- and age-based AD subpopulations. Showing only a moderate genetic correlation between younger (60-79 years old) and older ( $>80$ years old) age-at-onset AD subjects suggests that the polygenic architecture of $\mathrm{AD}$ is heterogeneous across age. However, stratified GWAS and polygenic variation analysis highlighted BIN1, OR2S2, and PICALM as having significant effects at a younger age [22]. Relative expression ordering (REO)-based gene expression profiling analyses revealed two distinct subtypes within $\mathrm{AD}$ patients - one where differentially expressed genes overlapped with age-related genes, and one related to neuroinflammation [23]. Since AD primarily affects older individuals, it is not surprising that the memory spared 
individuals were often younger and $A P O E \varepsilon 4$ negative compared to memory-impaired individuals [24]. Furthermore, in-depth latent class analysis (LCA) of subjects with $\mathrm{AD}$ dementia revealed eight cognitive subtypes associated with distinct demographical and neurobiological characteristics. For example, the memory spared moderate-visuospatial cluster was associated with younger age, $A P O E \varepsilon 4$ negative genotype, and prominent atrophy of the posterior cortex [25].

$A P O E \& 4$ allele frequency is consistently associated with more extensive ADassociated neuropathology and cognitive deficits [26]. It is evident that specific genetic variants, such as $A P O E \varepsilon 4$, have a more significant contribution to disease heterogeneity. The polygenic risk score (PRS) determines the cumulative genetic risk for an individual. Adopting a single nucleotide polymorphism (SNP) and transcriptomic approach when considering the PRS more accurately captures the contribution of individual SNPs and differential gene expression [12, 27]. Incorporating these strategies will contribute to the shift towards accurate patient stratification and classification, bringing precision medicine closer to reality. Rather than developing therapies for population averages of a biologically heterogeneous disease such as $\mathrm{AD}$, artificial intelligence (AI)-based algorithms can be utilized for more individually-tailored therapies [28].

Here we utilized a suite of machine learning tools designed to learn from patient/subject datasets to analyze gene expression data derived from postmortem controls vs. AD subjects. Importantly, these next-generation methods are capable of learning from smaller datasets than is typically assumed as necessary with many machine learning approaches and can explain the driving variables, as will be explained below. The novelty of this work lies in the machine's ability to discover unknown subpopulations that are defined by several genes at a time. These genes may be related to each other and the dependent variable, e.g., AD positive, in non-linear ways. The ability of some of these methods to extract non-linear relationships from small data is an exceptional trait. This ability, in combination with explainability and the ability to learn from small datasets, uncovers a new avenue of exploring patient 
populations. Collectively, these properties will equip researchers to redefine our understanding of disease heterogeneity and significantly move the needle forward on the precision treatment of disease. Further technical details will be provided in the Materials and Methods section.

\section{Materials and Methods}

A public AD dataset (GSE84422) consisting of transcriptomic data of postmortem brain samples from 121 healthy controls and $380 \mathrm{AD}$ subjects was assembled. A suite of machine learning methods that were uniquely assembled due to their ability to extract subpopulations from high dimensional data and their ability to provide explanations for the driving mechanisms behind the subpopulations were used. The methods can be reviewed here [29] and here [30]. These methods included statistical measures of feature importance, ensemble methods, neural networks, and a novel system designed to work with patient population data [31]. A significant feature of these machine intelligence methods is their ability to see a patient population in various ways. To be more precise, there are various ways to model a group of AD subjects vs. control subjects. Different collections of genes will reveal different relationships amongst the samples and different subtypes of subjects. These different models are called 'perspectives,' and this approach is referred to as Perspective Analytics. Each perspective is learned by the machine and consists of a unique set of variables, with each variable making a different contribution. The machine is rewarded for finding collections of samples that have several variables simultaneously in common, while those samples belong to the same perspective class. Thus, these methods are semi-supervised [29]. This particular machine intelligence utilizes geometric representation methods coupled with a fast learner. These methods were created specifically for use with smaller datasets; therefore, they are inherently designed not to try to find perfect models but instead find statistically significant pure subpopulations of a given label. 


\section{Results}

We were able to derive six progression mechanisms (i.e., perspective classes) that represent the various ways that an individual may manifest an AD pathology (Figure 1). An individual can progress via a single class or any combination of the six classes, highlighting the complexity of the AD population and resulting in 63 possible combinations. However, it is likely that there are even more mechanisms at play, including immune system function, which plays an important orchestration role, further contributing to the complex AD etiology.

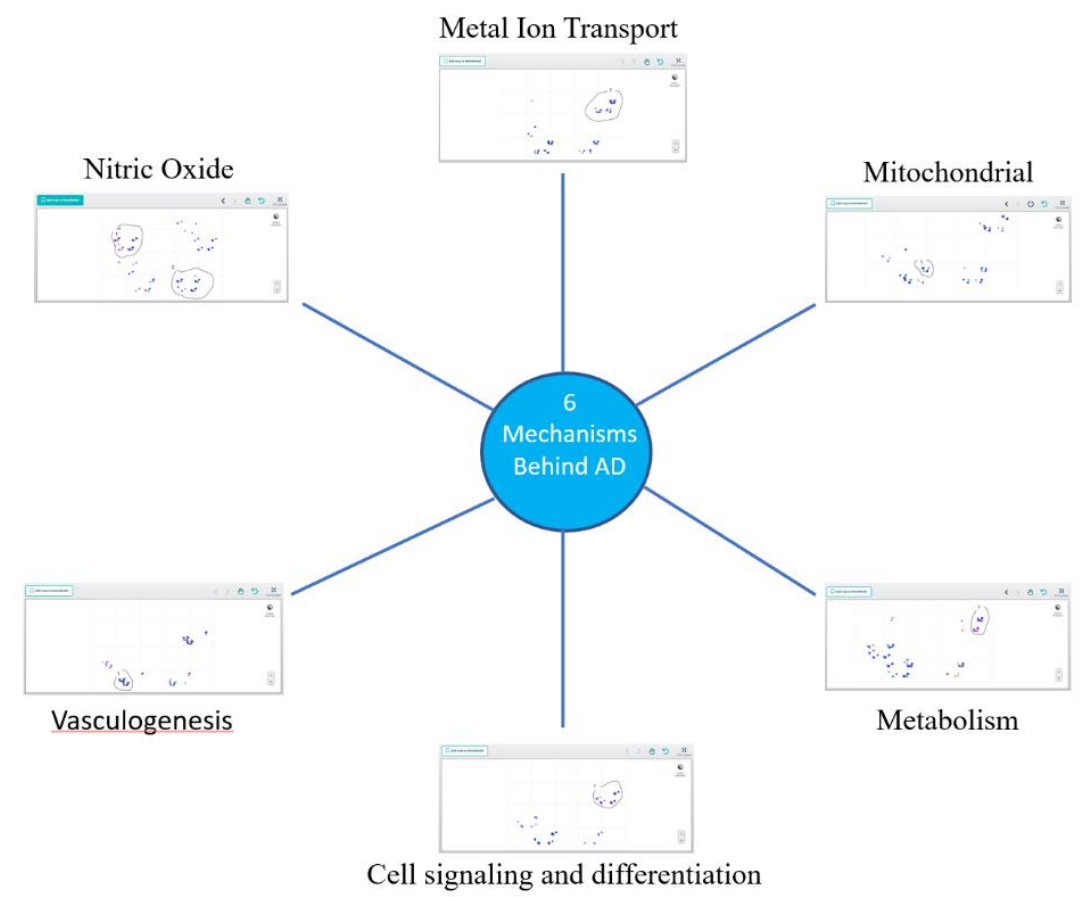

Figure 1. Perspective analytics for Alzheimer's disease. Perspective analytics discovered a unique set of variables for each of the six different perspectives learned from an Alzheimer's dataset. Within each set, there is a subgroup of subjects that are driven by the corresponding etiology.

While it is evident that small datasets are not representative of the overall disease state, the significant occurrence of variables binding together subjects of the same class can provide valuable insights with respect to precision medicine. Table 1 highlights characteristics of each perspective class, each of which represents a novel avenue of the complex etiologies that drive neurodegeneration and cognitive aging. Subjects that belong to more than one perspective class may be due to the overlapping 
components across some of the pathways implicated in each perspective class.

Table 1. Perspective classes, characteristic genes, and defining traits of AD patients.

\begin{tabular}{|c|c|c|c|c|}
\hline $\begin{array}{l}\text { Perspective } \\
\text { Class }\end{array}$ & $\begin{array}{l}\text { Number of } \\
\text { Subjects }\end{array}$ & Gene Name & Gene Symbol & Defining Trait \\
\hline \multirow[t]{3}{*}{ I } & \multirow[t]{3}{*}{156} & Tubulin beta 1 class VI & $T U B B 1$ & \multirow[t]{3}{*}{ Vasculogenesis } \\
\hline & & $\begin{array}{l}\text { Ankyrin repeat and suppressor of } \\
\text { cytokine signaling SOCS) box- } \\
\text { containing protein } 4\end{array}$ & $A S B 4$ & \\
\hline & & Phosphodiesterase 5A & $P D E 5 A$ & \\
\hline \multirow[t]{2}{*}{ II } & \multirow[t]{2}{*}{164} & Neuregulin 2 & $N R G 2$ & \multirow{2}{*}{$\begin{array}{l}\text { Cell Signaling and } \\
\text { Differentiation }\end{array}$} \\
\hline & & Zinc-finger 3 & $Z N F 3$ & \\
\hline \multirow[t]{3}{*}{ III } & \multirow[t]{3}{*}{84} & Insulin-like growth factor 1 & $I G F 1$ & \multirow[t]{3}{*}{ Metabolism } \\
\hline & & $\begin{array}{l}\text { Ankyrin repeat and suppressor of } \\
\text { cytokine signaling SOCS) box- } \\
\text { containing protein } 4\end{array}$ & $A S B 4$ & \\
\hline & & G2 and S-phase expressed protein 1 & GTSE1 & \\
\hline \multirow[t]{3}{*}{ IV } & \multirow[t]{3}{*}{134} & & cDNA FLJ39269 & \multirow[t]{3}{*}{ Nitric Oxide } \\
\hline & & Integrin subunit alpha & ITGA1 & \\
\hline & & Carboxypeptidase $\mathrm{M}$ & $C P M$ & \\
\hline \multirow[t]{3}{*}{$\mathbf{V}$} & \multirow[t]{3}{*}{76} & Phosphodiesterase 5A & $P D E 5 A$ & \multirow[t]{3}{*}{ Mitochondrial } \\
\hline & & Presenilin 1 & PSEN1 & \\
\hline & & NADH-coenzyme Q reductase & NDUFS8 & \\
\hline \multirow[t]{3}{*}{ VI } & \multirow[t]{3}{*}{228} & $\begin{array}{l}\text { DDB1 and CUL4 associated factor } \\
17\end{array}$ & $D C A F 17$ & \multirow[t]{3}{*}{ Metal Ion Transport } \\
\hline & & & cDNA FLJ75819 & \\
\hline & & Solute carrier family 33 member 1 & SLC33AI & \\
\hline
\end{tabular}

Due to reports of $\mathrm{AD}$ having a greater prevalence and severity in women, we investigated whether certain classes were more prevalent in females than males (Table 2). Interestingly the metal ion transport class was the most common, with $65 \%$ of the female $\mathrm{AD}$ subjects and $61 \%$ of the male $\mathrm{AD}$ subjects progressing via this class. Of the 266 female AD subjects, $49.6 \%$ progressed via the cell signaling class, compared to only $35.5 \%$ of the male subjects. Of the 90 male AD subjects, $58.9 \%$ fell under the vasculogenesis perspective class, compared to only $38.7 \%$ of the female subjects. 
Table 2. Sex-based differences in perspective classes of AD progression.

\begin{tabular}{|c|c|c|c|c|c|c|}
\hline \multicolumn{7}{|c|}{ Perspective Class } \\
\hline Sex & Vasculogenesis & $\begin{array}{c}\text { Cell } \\
\text { Signaling }\end{array}$ & Metabolism & $\begin{array}{l}\text { Nitric } \\
\text { Oxide }\end{array}$ & Mitochondrial & $\begin{array}{l}\text { Metal Ion } \\
\text { Transport }\end{array}$ \\
\hline Female & 103 & 132 & 60 & 104 & 44 & 173 \\
\hline Male & 53 & 32 & 24 & 30 & 32 & 55 \\
\hline Total & 156 & 164 & 84 & 134 & 76 & 228 \\
\hline
\end{tabular}

Class I is identified by $T U B B 1, A S B 4$, and $P D E 5 A$. As the primary identifier of Class

I, TUBB 1 mutations associated with enlarged rounded platelets and result in thrombocytopenia [32]. The strong link of AD to vascular diseases such as stroke and atherosclerosis, suggests a crucial role for vascularization in this subpopulation. Interestingly, there appears to be a network between $T U B B 1, A S B 4$, and PDE5A, suggesting that Class I represents a subpopulation defined by regulation of vasculogenesis (Figure 2) [33-35].

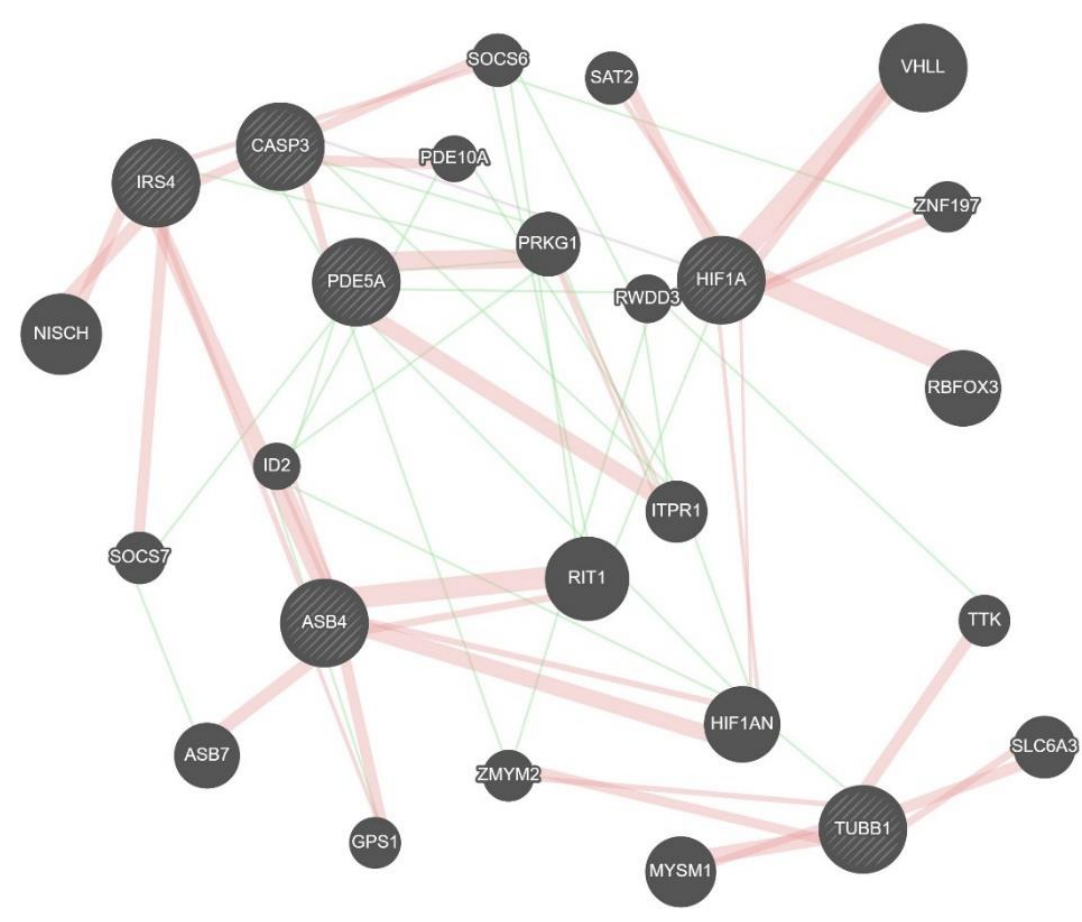

Figure 2. Gene interactions for Class I identifiers. Red represents physical interactions, purple represents co-expression, and green represents genetic interactions. Created using GeneMANIA [36].

NRG2 and ZNF3 define Class II. Neuregulins (NRGs) stimulate ErbB-receptor tyrosine phosphorylation that elicits different downstream signaling pathways such as MAPK, PI3, PKC, and JAK-STAT pathways and are associated with synaptic Journal Title 
plasticity $[37,38] . Z N F 3$ is a zinc-finger protein that is differentially expressed in AD and is involved in cell differentiation and proliferation [39]. Thus, we define Class II by cell signaling and differentiation.

Class III is defined by $I G F 1, A S B 4$, and GTSE1. Impairments in insulin/IGF1 signaling have been associated with $\mathrm{AD}[40,41]$. IGF1 is connected to ASB4 by IRS4 (insulin receptor substrate 4) and SOCS2 (Figure 3). In contrast, GTSE1 is a microtubule-associated protein that regulates G1/S cycle transition and microtubule stability [42]. Given the role of GTSE1 and TUBB1 on microtubule stability and formation, as well as the shared presence of $A S B 4$ as a descriptor in both Class I and Class III, these two classes may represent one larger overarching AD subpopulation that can be further stratified into microtubule formation and IGF1 pathway signaling. This is supported by the fact that the subjects which the machine clustered together in the metabolism class have lower expression levels of IGF1 than those we classified as being members of the vasculogenesis class.

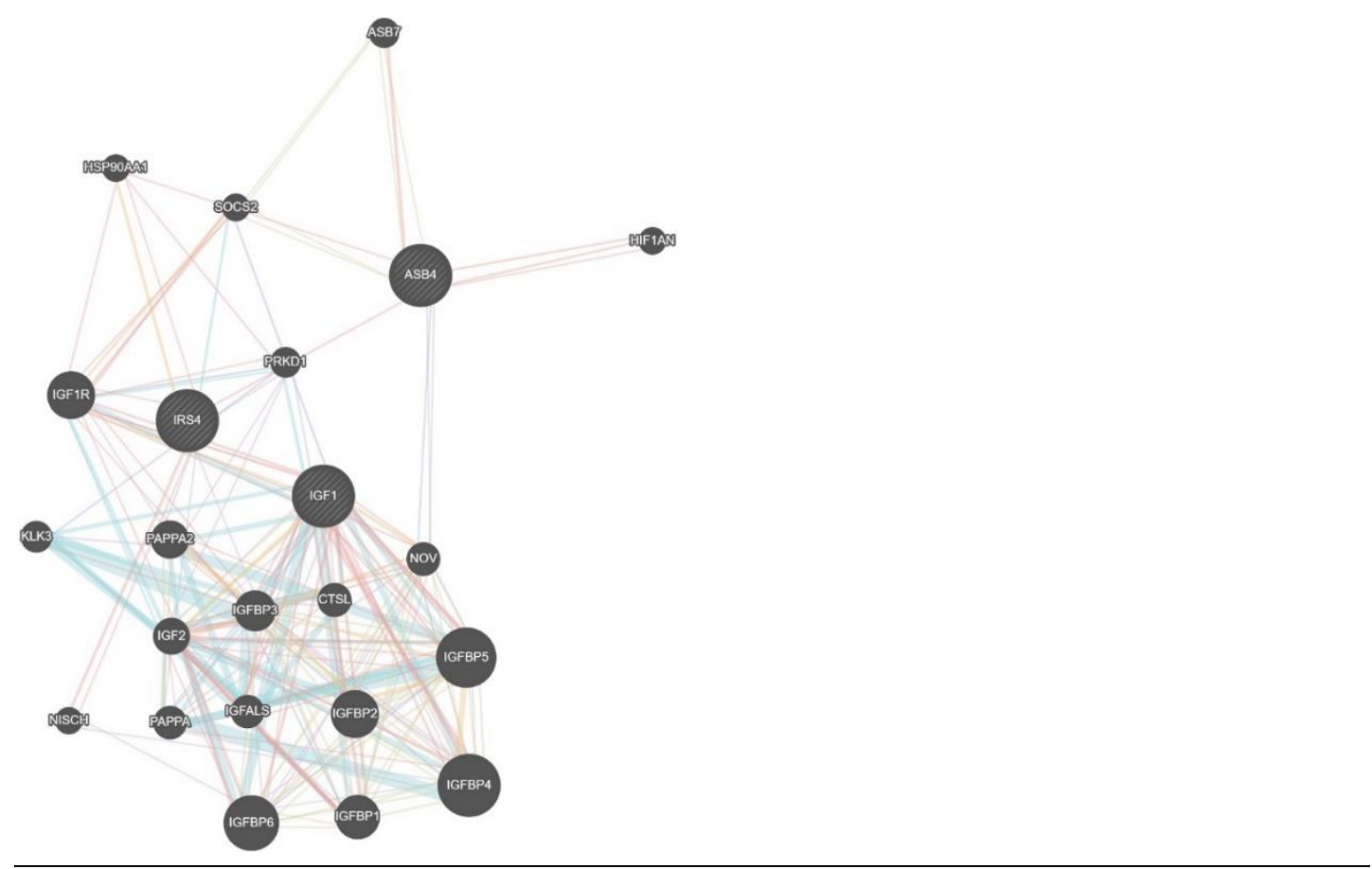

Figure 3. Gene interactions for Class III identifiers. Red represents physical interactions, purple represents co-expression, orange represents predicted interactions, blue represents co-localization, aqua represents a shared pathway, green represents genetic interactions, and yellow represents shared protein domains. Created using GeneMANIA [36]. 
Class IV is defined by cDNA FLJ39269, ITGA1, and CPM. cDNA FLJ39269 is most closely associated with GUCY1A3, which is dysregulated in $\mathrm{AD}[43,44]$. CPM is known to enhance nitric oxide output, playing a role in nitric oxide signaling under inflammatory conditions [45]. Due to the recurrent role of nitric oxide, we define Class IV with nitric oxide, despite ITGAI not being involved in this signaling.

Class V is defined by PDE5A, PSEN1, and NDUFS8. Despite PSEN1 mutations being one of the most common causes of familial AD (FAD), PSEN1 defined Class V to a lesser extent than PDE5A. Even within this population, $S Y K$ (spleen tyrosine kinase) is driving a difference within this group (Figure 4). The system is seeing the disease at multiple scales. NDUFS8 (NADH dehydrogenase (ubiquinone) Fe-S protein 8; $\mathrm{NADH}$-coenzyme Q reductase) along with other genes involved in oxidative phosphorylation are decreased in $\mathrm{AD}$ [46]. Given the role of these genes in mitochondrial function and redox, Class V was defined as mitochondrial.

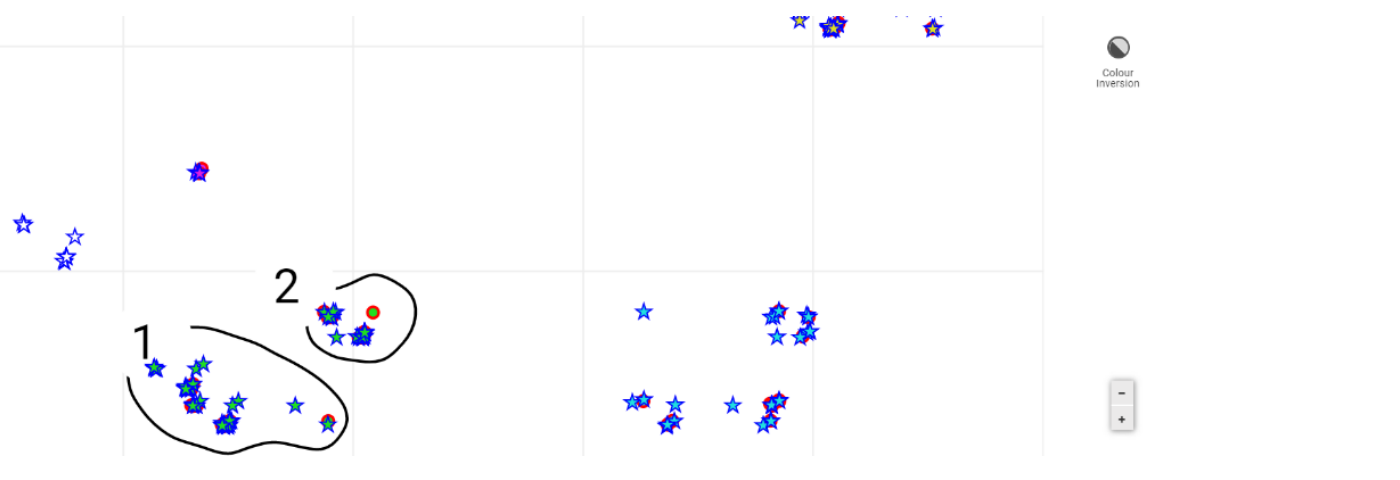

Figure 4. Sub-map of the AD population of Class V. This sub-map (zoomed in) provides another facet of the Alzheimer's population within this data set. From one perspective, PDE5A and PSEN1 are driving the relationships between the subjects illustrated. However, SYK is driving the slight separation between loop 1 and 2 .

Class VI is defined by DCAF17, cDNA FLJ75819, and SLC33A1. DCAF17 (DDB1 and CUL4 associated factor 17) is a nuclear transmembrane protein associated with damaged DNA binding protein 1 ubiquitin ligase complex and is involved in iron accumulation [47]. Given the mitochondrial role of the primary identifier of Class VI, there may be some overlap in subjects in Class V and VI. Interestingly, 44 subjects fell under both Class V and Class VI (Figure 5). cDNA FLJ75819 is most similar to 
ZNF652, which is associated with metal protein. With these two genes in mind, Class VI appears to be defined by metal ion metabolism.

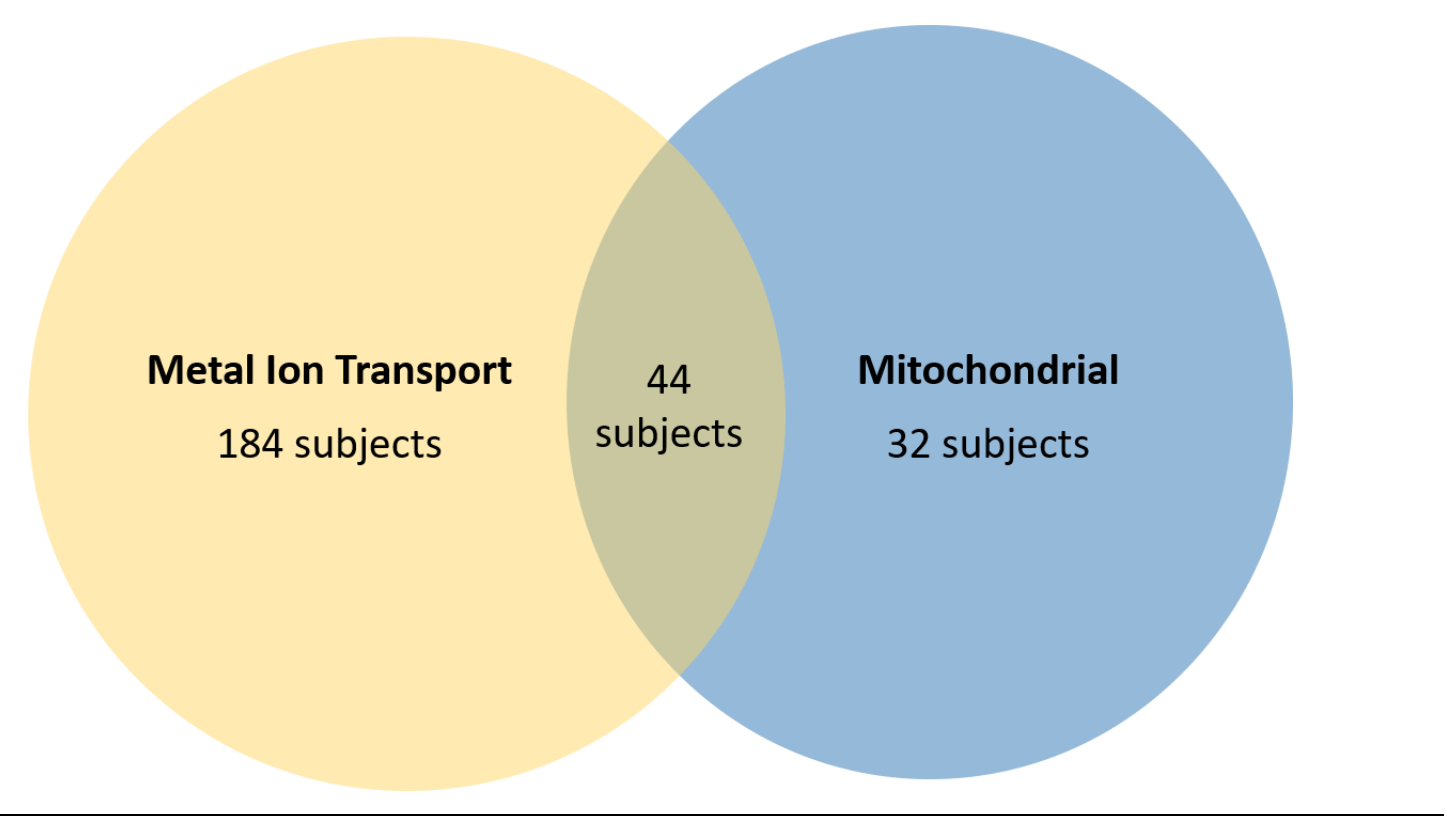

Figure 5. Overlap of subjects in the Metal Ion Transport and Mitochondrial perspective classes. A complete list of the AD samples from the data we used, in addition to which classes they fall in, is available in the supplementary materials.

\section{Discussion}

ML efforts in the field of Alzheimer's genomic research have been primarily focused on discovering subjects at-risk for $\mathrm{AD}$ or with high $\mathrm{MCI}-$ to-AD conversion. This work has been increasingly focused on identifying genetic subtypes within the presumption of a heterogeneous $\mathrm{AD}$ population. The need to expand biomarker-based stratification within the $\mathrm{AD}$ population has been highlighted with as many as 30 altered transcriptional signatures found to distinguish $\mathrm{AD}$ samples from non-demented brain samples [48]. However, there are currently few predictions for AD-associated genes based on brain gene expression data alone. This study sought to develop a brain-specific gene interaction network to predict the potential $\mathrm{AD}$ association for every gene in the genome by integrating the relationship between each pair of ADassociated genes and the correlation coefficient of known AD-associated and unassociated genes [49]. This genome-wide complement of AD candidate genes 
provides a precision medicine approach that can be used to explore AD mechanisms further and pave the path towards individualized novel treatments similar to what is already being done in cancer genomics.

Within the Class I identifiers, TUBB1 (Tubulin Beta 1 Class VI) encodes part of one of the core protein families that heterodimerize and assemble to form microtubules [50]. The tubulin $\beta-1$ chain is the major $\beta$-tubulin isotype expressed in megakaryocytes and platelets. Mutations or absence of $T U B B 1$ is associated with enlarged rounded platelets and result in thrombocytopenia [32]. TUBB1 has been reported to be downregulated in $\mathrm{AD}$; thus, it is not surprising that taxanes and other microtubule-targeting drugs restore lost nerve signals in $\mathrm{AD}$ and other neurodegenerative diseases [51]. The second Class I identifier, ASB4 (ankyrin repeat and suppressor of cytokine signaling (SOCS) box-containing protein 4). encodes a protein that degrades filamin B proteins and plays a role in vascular differentiation and insulin signaling [52]. Asb-4is co-localized and interacts with insulin receptor substrate 4 (IRS4) in hypothalamic neurons [53]. The Asb-4 and IRS4 interaction mediates the degradation of IRS4, which in turn decreases insulin signaling, implicating ASB4 in energy homeostasis [54]. Asb-4 has also been associated with the regulation of inflammation, angiogenesis, and apoptosis via interactions with factor inhibiting HIF-1 $\alpha$ (FIH) and TNF- $\alpha[55,56]$. Phosphodiesterases (PDEs) are responsible for the hydrolysis of cyclic adenosine monophosphate (cAMP) and cyclic guanosine monophosphate (cGMP). PDE inhibition is involved in neurodegenerative processes due to the regulation of cAMP and cGMP [57]. PDE5 is a cGMP-specific phosphodiesterase and is upregulated in AD subjects compared to age-matched healthy controls [58]. PDE5 inhibitors, such as Sildenafil, have been suggested as Alzheimer's drugs, leading to vascular smooth muscle relaxation, vasodilation, improved cognition, and restoring memory function [59-61]. Collectively, the Class I identifiers support the proposition of AD as a vascular disorder [33-35].

We described Class II by cellular signaling and differentiation due to being identified 
by $N R G 2$ and ZNF3. Neuregulins (NRGs) are a member of epidermal growth factor (EGF)-related proteins, which stimulate ErbB-receptor tyrosine phosphorylation that elicits different downstream signaling pathways such as MAPK, PI3, PKC, and JAKSTAT pathways and are associated with synaptic plasticity [37, 38]. Neuregulin-2 (Nrg2) dysregulation has been associated with cancer, schizophrenia, and AD [37]. Neuregulin-1 ( $\mathrm{Nrg} 1)$ is the primary substrate for BACE-1, which is the only $\beta$ secretase that generates $\mathrm{A} \beta$ peptides. Although $\mathrm{Nrg} 1$ and $\mathrm{Nrg} 2$ are highly homologous, it remains unclear whether $\mathrm{Nrg} 2$ is also a BACE-1 substrate [62]. However, ADAM10 and BACE-2 cleave $\mathrm{Nrg} 2$ to generate a C-terminal fragment that serves as a substrate for $\gamma$-secretase [63]. Little remains known about $N R G 2$; however, other members of the NRG family, including the more widely reported $N R G 1$ and less known $N R G 3$, have both been speculated to be involved in $\mathrm{AD}$ and cognitive impairment [64, 65]. In line with the overlying cell differentiation theme of Class II, ZNF3 is a transcription factor involved in cell differentiation and proliferation. In a recent GWAS, ZNF3 has been associated with $\mathrm{AD}$ along with NDUFS3 and MTCH2 [66]. ZNF3 interacts with $B A G 3$, which is involved in ubiquitin/proteasomal functions in protein degradation and is regulated by upstream binding of $B A C H 1$ whose target genes have roles in the oxidative stress response and control of the cell cycle [67]. ADassociated tau has been identified as a $\mathrm{BACH} 1$ target, making it a potential $\mathrm{AD}$ target [68]. However, a clear link explaining this subpopulation remains to be identified and warrants further investigations.

We propose that Class III, which is defined by IGF1, ASB4, and GTSE1 to be classified by metabolism. Several studies have reported on impaired insulin receptor/IGF1 receptor signaling in $\mathrm{AD}$ subjects with receptor expression decreased, suggesting that $\mathrm{AD}$ is brain-type diabetes [69]. However, the association between IGF1 and AD remains controversial [70, 71]. Low IGF1 serum levels are associated with aging, which is one of the significant risk factors for AD. This suggests that high IGF1 may protect against neurodegeneration [56]. Some studies report that IGF1 enhances the transport of $A \beta$-carrier proteins into the brain and promoting transport 
across the blood-brain barrier [72]. In contrast, other studies have shown that longterm suppression of IGF1R signaling alleviates AD progression, providing protection from neuroinflammation and memory impairments induced by A $\beta$ oligomers [73]. A recent study identified that within $A P O E \& 4$ carriers, there is a threshold at which IGF1R stimulating activity becomes associated with dementia [74]. Thus, IGF1 expression and response to IGF1 signaling may present as a way to stratify AD subjects into different subtypes. One study suggests that IRS4 may be a negative regulator of IGF1 signaling by suppressing the function of other IRS proteins [75]. Given this link, the IGF1 signaling pathway presents an interesting way to classify AD subpopulations. IRS4 has been found to be the most downregulated gene in the insulin signaling pathway, with IRS genes implicated in tau phosphorylation [76]. Asb-4 co-localization with IRS4 mediates IRS4 degradation, which in turn decreases insulin signaling [53]. Increased $A S B 4$ would promote decreased insulin signaling as would IRS4 downregulation. Given this link, the IGF1 signaling pathway represents a unique classification of AD subpopulations, as increased ASB4 would promote decreased insulin signaling as would IRS4 downregulation. Considering GTSE1, which encodes a microtubule-associated protein, as the third prevalent identifier for Class III, there is overlap between Class I and Class III. Both TUBBI and GTSE1 are involved in microtubule stability and formation, and both classes are defined by $A S B 4$. Thus, these two classes may actually represent one larger subpopulation that can further be defined or stratified on the basis of insulin/insulin-like growth factor signaling.

Class IV was defined by cDNA FLJ39269, ITGA1, and CPM. As mentioned, GUCY1A3 is the most closely associated gene to cDNA FLJ39269. GUCY1A3 encodes for a subunit of the guanylyl cyclase, a key enzyme in the nitric oxide signaling pathway, which catalyzes the conversion of GTP to cGMP, which in turn regulates the activity of protein kinases, PDEs, and ion channels [77]. Furthermore, GUCY1A3 has been associated with vascular dementia [78]. GUCY1A3 mutations are associated with nitric oxide signaling disruption that leads to hypertension [79]. In 
contrast, ITGA1 encodes the $\alpha 1$ subunit of integrin receptors, which heterodimerizes with the $\beta 1$ subunit to form a cell-surface receptor for collagen and laminin [80]. More specifically, the $\alpha 1 \beta 1$ complex has been associated with mediating the $A \beta$ neurotoxic effect, playing an essential role in initiating events that lead to neurite degeneration in the presence of $\mathrm{A} \beta$ [81]. ITGA1 has been found to be downregulated in neuroplastin 65 (NP65) knockout mice, which exhibit abnormal cognition and emotional disorders that resemble $\mathrm{AD}$ characteristics [82]. CPM is a carboxypeptidase for peptides and proteins involved in inflammation and neuropeptide processing and has been found to be downregulated in the lymphocytes of $\mathrm{AD}$ subjects [83]. CPM is known to enhance nitric oxide output, playing a role in nitric oxide signaling under inflammatory conditions [45]. The AD patient population is characterized by chronic inflammation in the brain and are increasingly susceptible to infections, suggesting a possible link between $C P M$ and $\mathrm{AD}$ [84]. Nitric oxide has been implicated in $\mathrm{AD}$ neurotoxicity as nitric oxide-dependent pathways have been reported to contribute to cognitive decline and neurodegeneration [85]. As an inflammatory disease, nitric oxide synthesis is increased in the AD brain, which is thought to contribute to oxidative stress-associated neurodegeneration. However, there are reports of an early neuroprotective role of nitric oxide in AD that may be harnessed as a therapeutic strategy [86]. NO has been reported to impair autophagy by several mechanisms, with NOS inhibition enhancing clearance of autophagic substrates and reducing neurodegeneration [87]. However, autophagy impairment has been reported in individuals with neurodegenerative diseases, and the causal mechanistic links between NO, autophagy and AD remain to be elucidated $[88,89]$. Furthermore, there have been links with other carboxypeptidases to AD. Specifically, a new human mutation in the carboxypeptidase $\mathrm{E}(\mathrm{CPE}) /$ neurotrophic factor- $\alpha 1$ (NF- $\alpha 1)$ gene from an $\mathrm{AD}$ patient was found to cause memory deficit and depressive-like behavior in transgenic mice [90]. Thus, this AD subpopulation appears to be linked to nitric oxide, which has been implicated om AD neurodegeneration. 
mitochondrial subpopulation, that may suggest a familial role. PDE5 is upregulated in AD subjects compared to age-matched healthy controls, underscoring the use of PDE5 inhibitors to restore memory function and cognition $[58,59]$. Even further, PDE5 inhibition has been shown to decrease A $\beta$ load in models of AD [91]. Although $P D E 5 A$ was the third most prominent identifier for Class I, it was the primary identifier for Class V. PDE inhibition is involved in neurodegenerative processes by regulating cAMP and cGMP concentrations [57]. cGMP-specific PDE5 is reported to be upregulated in $\mathrm{AD}$ subjects compared to age-matched healthy controls [58].m What stood out the most for this Class was that although PSEN1 mutations are the most common cause of FAD, PSEN1 was not the primary identifier for this Class. There are two hypotheses that describe the role of PSEN1 on AD pathogenesis - the amyloid hypothesis and the presenilin hypothesis. The amyloid hypothesis proposes that PSEN1 mutations initiate AD pathogenesis by increasing the production of $A \beta 42$, which contributes to amyloid plaque deposition. In contrast, the presenilin hypothesis proposes that PSEN1 mutations cause loss of function of presenilin in the brain, which in turn triggers neurodegeneration and dementia [92]. Looking even further into this subpopulation, we noticed that $S Y K$ drives an additional difference within this group, also highlighting the complexity of the disease. $S Y K$ regulates $\mathrm{A} \beta$ production and tau hyperphosphorylation $[93,94]$. The $\mathrm{A} \beta$ and the nitric oxide (NO)/cGMP pathway can stimulate synaptic plasticity and memory at low doses and inhibit them at high doses. With aging, the body's ability to regulate the balance between oxidant and antioxidant systems decreases, resulting in an increased production of reactive oxygen and nitrogen species that result in tissue damage. This oxidative stress also promotes the accumulation of $\mathrm{A} \beta$ [91]. Furthermore, NDUFS 8 being one of the identifiers for Class V highlights the mitochondrial role of AD. Complex I has essential bioenergetic and metabolic functions and is a known source of reactive oxygen species, linking it to many hereditary and degenerative diseases [95].

Class VI was defined by DCAF17, cDNA FLJ75819, and SLC33A1. DCAF17 encodes a nuclear transmembrane protein associated with damaged DNA binding protein 1 
ubiquitin ligase complex and is involved in iron accumulation in Globus pallidus and in white matter [47]. Similar to Class V, this highlights the role of mitochondrial dysfunction in AD pathogenesis. Within Class VI specifically, this highlights the pathological role of iron overload in the mitochondria to cause mitochondrial dysfunction [96]. It appears that iron overload-induced mitochondrial dysfunction is the driving difference between Class V and Class VI. This idea is reinforced with ZNF652, which, although not the identifier for Class VI, is the most closely associated gene to cDNA FLJ75819. ZNF652 is associated with metal protein and has been reported to be upregulated in severe $\operatorname{AD}[97,98]$. The third identifier of this subpopulation, SLC33A1, and its associated protein AT-1, is associated with the import of acetyl-CoA by regulating Ne-lysine acetylation of ER-resident and transiting proteins which causes a progeria-like phenotype that mimics an accelerated form of aging [99]. Mutations and increased expression of AT-1/SLC33A1 have been associated with several diseases neurologic, intellectual, and dysmorphic conditions, and has also been reported in LOAD subjects [100]. Interestingly, SLC33A1 mutations have also been associated with low serum copper [101]. Homeostasis of metal ions, including iron, copper, zinc, and calcium, in the brain is crucial for maintaining normal physiological functions - and an imbalance is closely related to the onset and progression of $\mathrm{AD}$. This is due to metal ion dysregulation contribute to oxidative stress and induce tau and $A \beta$ pathologies [102]. Although there appears to be an underlying role of metals or metal metabolism, this represents a subpopulation that warrants additional investigation to understand how they collectively contribute to AD pathology.

Interestingly, aside from PSEN1, the genes primarily associated with $\mathrm{AD}$ and increased AD risk - $A P O E \& 4, A P P, P S E N 1$, and PSEN2 were not the primary identifiers for any $\mathrm{AD}$ perspective. This highlights the heterogeneous nature of $\mathrm{AD}$ pathology. Furthermore, there have been reports on the molecular differences in AD between males and females [103]. Thus, identifying whether certain classes or combinations of classes are more prevalent in males or females will continue to shed 
light on disease etiology. Females are at a greater risk of developing AD dementia, while males are at a greater risk of developing vascular dementia [104]. Analysis of our dataset revealed that $58.9 \%$ of males fell under the vasculogenesis perspective class, compared to only $38.7 \%$ of females. Surprisingly, only $16.5 \%$ of females fell under the mitochondrial perspective class. Gender has been reported to not only influence AD evolution directly but also through other comorbidity factors [105]. Note that the perspective classes discovered by the machine intelligence we are using offers a view into how $\mathrm{AD}$ progresses for different people and how different people evolve towards this phenotype through potentially different combinations of factors. The six progression mechanisms discussed here appear to be an essential part of this story. By providing an increased granularity into the mechanisms at play, the advent of AI and ML algorithms provide a means of expediting the drug repurposing and development process, particularly with respect to heterogeneous neurodegenerative diseases. This is because ML approaches permit the mining of different kinds of data that shed light on disease etiology through precise subpopulations, which can, in turn, assist in the discovery and development of effective anti-AD drugs. Future work will explore statistical evaluations of several subpopulations.

It is widely known that $\mathrm{AD}$ is a heterogeneous disease, yet $\mathrm{AD}$ drug trials often have broad inclusion criteria, not accounting for disease heterogeneity in trial design [106108]. Stratifying treatment trial designs to account for disease heterogeneity using algorithms and omics data will lead to personalized medicine in AD drug development. Hypothesis generating AI technologies like the one described in [28] are able to help usher in disease definitions that precisely relate to the molecular machinery at play. The improvement to clinical trial outcomes can be substantial as we will be better able to select patients and match them with drug candidates. Perspective Analytics allowed us to understand an $\mathrm{AD}$ patient population in various ways with the goal of being able to precisely define the various mechanisms at play behind this complex disease, and how these perspectives can improve clinical trial efforts in this space. It is possible that certain drugs that have been designed for AD 
are actually effective at improving the health of certain subpopulations, and even more possible that several drug candidates can be repositioned for specific subtypes. Here, we have identified six perspective classes corresponding to disease progression mechanisms that contribute to AD heterogeneity. The six perspective classes highlight the critical roles of vasculogenesis, cellular signaling and differentiation, metabolic function, mitochondrial function, nitric oxide, and metal ion metabolism. Although these specific AD patient subpopulations have not explicitly been identified previously, the genetic identifiers for each perspective have been implicated in AD. The ability to utilize a small dataset to extract such precise insights opens up the possibility to boil away much of the noise that exists within the AD field, redefining the way we think about $\mathrm{AD}$ as a set of diseases that emerge through various molecular pathways.

\section{Conclusions}

Many exceptional advances using machine intelligence have been made over the last several years. Computer vision applications have been given particular attention as the advent of convolutional neural networks are beautifully suited for these tasks. Similarly, other types of deep neural networks are currently being used for drug discovery. There is great potential that comes with creating a new taxonomy of disease for complex disorders. These efforts will allow researchers and pharmaceutical companies to derive precise and novel ways to attack these disorders either through the drug paradigm or genetic engineering.

Although results from this study are not exhaustive, they demonstrate that even within a relatively small study sample, next-generation machine intelligence is capable of uncovering multiple genetically driven subtypes. We hope to continue this work with a larger Alzheimer's transcriptomic data set so that we can continue to unravel the etiology behind dementia. In future analyses, we are considering the combinatorial aspects of the patient population within this data set and from others. Are there certain 
combinations of the six perspective classes that are statistically more likely to occur? Machine intelligence has opened up a door that is allowing us to pursue therapies for neurodegeneration with a much finer granularity of understanding.

\section{Abbreviations}

A $\beta$ : $\beta$-amyloid

AI: Artificial intelligence

AD: Alzheimer's disease

cAMP: Cyclic adenosine monophosphate

cGMP: Cyclic guanosine monophosphate

CSF: Cerebrospinal fluid

DMT: Disease-modifying therapy

EOAD: Early onset Alzheimer's disease

FAD: Familial Alzheimer's disease

FIH: Factor inhibiting HIF-1 $\alpha$

GWAS: Genome-wide association study

IRS: Insulin receptor substrate

LCA: Latent class analysis

LOAD: Late onset Alzheimer's disease

MCI: Mild cognitive impairment

MFMR: Multi-trait Finite Mixture of Regressions

ML: Machine learning

MRI: Magnetic resonance imaging

NGS: Next generation sequencing

NO: Nitric oxide 
NRG: Neuregulin

PDE: Phosphodiesterase

PET: Positron emission tomography

PRS: Polygenic risk score

RGWAS: Reverse genome-wide association study

REO: Relative expression ordering

SOCS: Suppressor of cytokine signaling

SNP: Single nucleotide polymorphism

SVM: Support vector machine

SYK: Spleen tyrosine kinase

\section{Declarations}

\section{Author contributions}

JG created the mathematics from which the machine intelligence techniques utilized were derived, curated the data, led the vision, and carried out a good portion of the research along with MT who contributed vital bioinformatics. BQ (first author) wrote the majority of the manuscript and also carried out critical protein interaction work that allowed us to interpret the results provided by the machine intelligence. RA and AA were both primary readers of the manuscript, provided direction, criticism, and helped shape the overall flow of the research during the course of this work.

\section{Conflicts of interest}

The author Joseph Geraci declares that he owns substantial shares in NetraMark Corp, which funded a major portion of this study.

\section{Ethical approval}

Not applicable. 


\section{Consent to participate}

Not Applicable.

\section{Consent to publication}

Not applicable.

\section{Availability of data and materials}

The data for this work was extracted from data available at

https://www.ebi.ac.uk/arrayexpress/experiments/E-GEOD-84422/?query=GSE84422

\section{Funding}

This project was supported by NetraMark Corp, an AI company focused on advanced machine intelligence methods and by graduate student support from Queen's University for Bessi Qorri.

\section{Copyright}

(C) The Author(s) 2020.

\section{References}

1. Organization WH. Global action plan on the public health response to dementia 2017-2025. In. Geneva; 2017. (ISBN No. 9241513489)

2. 2020 Alzheimer's disease facts and figures. In; 2020, p. 391-460. (ISBN No. 1552-5260)

3. Prince M, Ali G-C, Guerchet M, Prina AM, Albanese E, Wu Y-T. Recent global trends in the prevalence and incidence of dementia, and survival with dementia. Alzheimer's Research \& Therapy. 2016;8:23.

4. Toro CA, Zhang L, Cao J, Cai D. Sex differences in Alzheimer's disease: Understanding the molecular impact. Brain research. 2019;1719:194-207.

5. Quan M, Zhao T, Tang Y, Luo P, Wang W, Qin Q, et al. Effects of gene mutation and disease progression on representative neural circuits in familial Alzheimer's disease. Alzheimer's Research \& Therapy. 2020;12:14.

6. Dorszewska J, Prendecki M, Oczkowska A, Dezor M, Kozubski W. Molecular basis of familial and sporadic Alzheimer's disease. Current Alzheimer Research. 2016;13:952-63.

7. Anand R, Gill KD, Mahdi AA. Therapeutics of Alzheimer's disease: Past, present and future. 
Neuropharmacology. 2014;76:27-50.

8. Eid A, Mhatre I, Richardson JR. Gene-environment interactions in Alzheimer's disease: a potential path to precision medicine. Pharmacology \& Therapeutics. 2019;199:173-87.

9. Cummings J, Lee G, Ritter A, Zhong K. Alzheimer's disease drug development pipeline: 2018. Alzheimer's \& Dementia: Translational Research \& Clinical Interventions. 2018;4:195-214.

10. Cummings JL, Morstorf T, Zhong K. Alzheimer's disease drug-development pipeline: few candidates, frequent failures. Alzheimer's Research \& Therapy. 2014;6:37.

11. Wang X, Sun G, Feng T, Zhang J, Huang X, Wang T, et al. Sodium oligomannate therapeutically remodels gut microbiota and suppresses gut bacterial amino acids-shaped neuroinflammation to inhibit Alzheimer's disease progression. Cell research. 2019;29:787803.

12. Hampel H, O’Bryant S, Castrillo J, Ritchie C, Rojkova K, Broich K, et al. Precision medicinethe golden gate for detection, treatment and prevention of Alzheimer's disease. The journal of prevention of Alzheimer's disease. 2016;3:243.

13. Freudenberg-Hua Y, Li W, Davies P. The role of genetics in advancing precision medicine for Alzheimer's disease - a narrative review. Frontiers in medicine. 2018;5:108.

14. Van Cauwenberghe C, Van Broeckhoven C, Sleegers K. The genetic landscape of Alzheimer disease: clinical implications and perspectives. Genetics in Medicine. 2016;18:421-30.

15. Lambert J-C, Ibrahim-Verbaas CA, Harold D, Naj AC, Sims R, Bellenguez C, et al. Metaanalysis of 74,046 individuals identifies 11 new susceptibility loci for Alzheimer's disease. Nature genetics. 2013;45:1452.

16. Tábuas-Pereira M, Santana I, Guerreiro R, Brás J. Alzheimer's Disease Genetics: Review of Novel Loci Associated with Disease. Current Genetic Medicine Reports. 2020;8:1-16.

17. Castrillo JI, Lista S, Hampel H, Ritchie CW. Systems biology methods for Alzheimer's disease research toward molecular signatures, subtypes, and stages and precision medicine: application in cohort studies and trials. In: editor^editors, editor. Biomarkers for Alzheimer's Disease Drug Development:Springer;2018.p.31-66.

18. Zhang D, Wang Y, Zhou L, Yuan H, Shen D, Initiative AsDN. Multimodal classification of Alzheimer's disease and mild cognitive impairment. Neuroimage. 2011;55:856-67.

19. Wei R, Li C, Fogelson N, Li L. Prediction of conversion from mild cognitive impairment to alzheimer's disease using mri and structural network features. Frontiers in aging neuroscience. 2016;8:76.

20. Zhang D, Shen D, Initiative AsDN. Multi-modal multi-task learning for joint prediction of multiple regression and classification variables in Alzheimer's disease. NeuroImage. 2012;59:895-907.

21. Zhang D, Shen D, Initiative AsDN. Predicting future clinical changes of MCI patients using longitudinal and multimodal biomarkers. PloS one. 2012;7.

22. Lo M-T, Kauppi K, Fan C-C, Sanyal N, Reas ET, Sundar V, et al. Identification of genetic heterogeneity of Alzheimer's disease across age. Neurobiology of aging. 2019;84:243. e1-. e9.

23. Hong G, Zeng P, Li N, Cai H, Guo Y, Li X, et al. A Qualitative Analysis Based on Relative Expression Orderings Identifies Transcriptional Subgroups for Alzheimer's Disease. Current Alzheimer Research. 2019.

24. Scheltens NM, Tijms BM, Koene T, Barkhof F, Teunissen CE, Wolfsgruber S, et al. Cognitive subtypes of probable Alzheimer's disease robustly identified in four cohorts. Alzheimer's \& 
Dementia. 2017;13:1226-36.

25. Scheltens NM, Galindo-Garre F, Pijnenburg YA, van der Vlies AE, Smits LL, Koene T, et al. The identification of cognitive subtypes in Alzheimer's disease dementia using latent class analysis. Journal of Neurology, Neurosurgery \& Psychiatry. 2016;87:235-43.

26. Crane PK, Trittschuh E, Mukherjee S, Saykin AJ, Sanders RE, Larson EB, et al. Incidence of cognitively defined late-onset Alzheimer's dementia subgroups from a prospective cohort study. Alzheimer's \& Dementia. 2017;13:1307-16.

27. Chasioti D, Yan J, Nho K, Saykin AJ. Progress in polygenic composite scores in Alzheimer's and other complex diseases. Trends in Genetics. 2019.

28. Gong C-X, Liu F, Iqbal K. Multifactorial hypothesis and multi-targets for Alzheimer's disease. Journal of Alzheimer's Disease. 2018;64:S107-S17.

29. Tsay M, Geraci J, Agrawal A. Next-gen AI for Disease Definition, Patient Stratification, and Placebo Effect. 2020.

30. Silva GA. The Effect of Signaling Latencies and Node Refractory States on the Dynamics of Networks. Neural Computation. 2019;31:2492-522.

31. Rokach L. Ensemble Learning: Pattern Classification Using Ensemble Methods:World Scientific Publishing Co Pte Ltd;2019.

32. Burley K, Westbury SK, Mumford AD. TUBB1 variants and human platelet traits. Platelets. 2018;29:209-11.

33. De la Torre J. Vascular basis of Alzheimer's pathogenesis. Annals of the New York Academy of sciences. 2002;977:196-215.

34. de la Torre JC. Is Alzheimer's disease a neurodegenerative or a vascular disorder? Data, dogma, and dialectics. The Lancet Neurology. 2004;3:184-90.

35. Altman R, Rutledge JC. The vascular contribution to Alzheimer's disease. Clinical science. 2010;119:407-21.

36. Warde-Farley D, Donaldson SL, Comes O, Zuberi K, Badrawi R, Chao P, et al. The GeneMANIA prediction server: biological network integration for gene prioritization and predicting gene function. Nucleic Acids Res. 2010;38:W214-20.

37. Kim JA, Jayabalan AK, Kothandan VK, Mariappan R, Kee Y, Ohn T. Identification of Neuregulin-2 as a novel stress granule component. BMB reports. 2016;49:449.

38. Ledonne A, Mercuri NB. On the Modulatory Roles of Neuregulins/ErbB Signaling on Synaptic Plasticity. International Journal of Molecular Sciences. 2020;21:275.

39. Islam T, Islam MRR, Shahjaman M, Zaman T, Karim MR, Quinn JM, et al. Blood-based molecular biomarker signatures in Alzheimer's disease: Insights from systems biomedicine perspective. bioRxiv. 2018:481879.

40. Freude S, Hettich MM, Schumann C, Stöhr O, Koch L, Köhler C, et al. Neuronal IGF-1 resistance reduces $A \beta$ accumulation and protects against premature death in a model of Alzheimer's disease. The FASEB Journal. 2009;23:3315-24.

41. Wu M, Fang K, Wang W, Lin W, Guo L, Wang J. Identification of key genes and pathways for alzheimer's disease via combined analysis of genome-wide expression profiling in the hippocampus. Biophysics Reports. 2019;5:98-109.

42. Tipton AR, Wren JD, Daum JR, Siefert JC, Gorbsky GJ. GTSE1 regulates spindle microtubule dynamics to control Aurora B kinase and Kif4A chromokinesin on chromosome arms. Journal of Cell Biology. 2017;216:3117-32. 
43. Puthiyedth N, Riveros C, Berretta R, Moscato P. Identification of Differentially Expressed Genes through Integrated Study of Alzheimer's Disease Affected Brain Regions. PloS one. 2016;11:e0152342-e.

44. Kessler T, Wobst J, Wolf B, Eckhold J, Vilne B, Hollstein R, et al. Functional characterization of the GUCY1A3 coronary artery disease risk locus. Circulation. 2017;136:476-89.

45. Zhang X, Tan F, Brovkovych V, Zhang Y, Lowry JL, Skidgel RA. Carboxypeptidase M augments kinin $\mathrm{B} 1$ receptor signaling by conformational crosstalk and enhances endothelial nitric oxide output. Biological chemistry. 2013;394:335-45.

46. Lunnon K, Keohane A, Pidsley R, Newhouse S, Riddoch-Contreras J, Thubron EB, et al. Mitochondrial genes are altered in blood early in Alzheimer's disease. 2017;53:36-47.

47. Arber CE, Li A, Houlden H, Wray S. Review: Insights into molecular mechanisms of disease in neurodegeneration with brain iron accumulation: unifying theories. Neuropathology and applied neurobiology. 2016;42:220-41.

48. Dagan H, Flashner-Abramson E, Vasudevan S, Jubran MR, Cohen E, Kravchenko-Balasha N. Exploring Alzheimer's Disease Molecular Variability via Calculation of Personalized Transcriptional Signatures. Biomolecules. 2020;10:503.

49. Huang X, Liu H, Li X, Guan L, Li J, Tellier LCAM, et al. Revealing Alzheimer's disease genes spectrum in the whole-genome by machine learning. BMC neurology. 2018;18:5.

50. Kim JH, Franck J, Kang T, Heinsen H, Ravid R, Ferrer I, et al. Proteome-wide characterization of signalling interactions in the hippocampal CA4/DG subfield of patients with Alzheimer's disease. Scientific Reports. 2015;5:11138.

51. Morello G, Cavallaro S. Transcriptional analysis reveals distinct subtypes in amyotrophic lateral sclerosis: implications for personalized therapy. Future medicinal chemistry. 2015;7:1335-59.

52. Upadhyay A, Joshi V, Amanullah A, Mishra R, Arora N, Prasad A, et al. E3 ubiquitin ligases neurobiological mechanisms: development to degeneration. Frontiers in molecular neuroscience. 2017;10:151.

53. Li J-Y, Chai B, Zhang W, Wu X, Zhang C, Fritze D, et al. Ankyrin repeat and SOCS box containing protein 4 (Asb-4) colocalizes with insulin receptor substrate 4 (IRS4) in the hypothalamic neurons and mediates IRS4 degradation. BMC neuroscience. 2011;12:95.

54. Li JY, Kuick R, Thompson R, Misek D, Lai YM, Liu YQ, et al. Arcuate Nucleus Transcriptome Profiling Identifies Ankyrin Repeat and Suppressor of Cytokine Signalling Box-Containing Protein 4 as a Gene Regulated by Fasting in Central Nervous System Feeding Circuits. Journal of neuroendocrinology. 2005;17:394-404.

55. Anasa VV, Ravanan P, Talwar P. Multifaceted roles of ASB proteins and its pathological significance. Frontiers in Biology. 2018;13:376-88.

56. Westwood AJ, Beiser A, DeCarli C, Harris TB, Chen TC, He X-m, et al. Insulin-like growth factor-1 and risk of Alzheimer dementia and brain atrophy. Neurology. 2014;82:1613-9.

57. Wu Y, Li Z, Huang Y-Y, Wu D, Luo H-B. Novel Phosphodiesterase Inhibitors for Cognitive Improvement in Alzheimer's Disease: Miniperspective. Journal of medicinal chemistry. 2018;61:5467-83.

58. Zhou L-y, Zhu Y, Jiang Y-r, Zhao X-j, Guo D. Design, synthesis and biological evaluation of dual acetylcholinesterase and phosphodiesterase $5 \mathrm{~A}$ inhibitors in treatment for Alzheimer's disease. Bioorganic medicinal chemistry letters. 2017;27:4180-4. 
59. García-Osta A, Cuadrado-Tejedor M, García-Barroso C, Oyarzabal J, Franco R. Phosphodiesterases as therapeutic targets for Alzheimer's disease. ACS chemical neuroscience. 2012;3:832-44.

60. Sanders O. Sildenafil for the Treatment of Alzheimer's Disease: A Systematic Review. Journal of Alzheimer's Disease Reports. 2020;4:91-106.

61. Liu L, Xu H, Ding S, Wang D, Song G, Huang X. Phosphodiesterase 5 inhibitors as novel agents for the treatment of Alzheimer's disease. Brain research bulletin. 2019.

62. Hu X, Fan Q, Hou H, Yan R. Neurological dysfunctions associated with altered BACE 1dependent Neuregulin-1 signaling. Journal of neurochemistry. 2016;136:234-49.

63. Czarnek M, Bereta J. Proteolytic Processing of Neuregulin 2. Molecular Neurobiology. 2019:1-15.

64. Cespedes JC, Liu M, Harbuzariu A, Nti A, Onyekaba J, Cespedes HW, et al. Neuregulin in Health and Disease. International journal of brain disorder and treatment. 2018;4.

65. Wang K-S, Xu N, Wang L, Aragon L, Ciubuc R, Arana TB, et al. NRG3 gene is associated with the risk and age at onset of Alzheimer disease. Journal of neural transmission. 2014;121:183-92.

66. Naj AC, Schellenberg GD, Consortium AsDG. Genomic variants, genes, and pathways of Alzheimer's disease: an overview. American Journal of Medical Genetics Part B: Neuropsychiatric Genetics. 2017;174:5-26.

67. Escott-Price V, Bellenguez C, Wang L-S, Choi S-H, Harold D, Jones L, et al. Gene-wide analysis detects two new susceptibility genes for Alzheimer's disease. 2014;9.

68. Warnatz H-J, Schmidt D, Manke T, Piccini I, Sultan M, Borodina T, et al. The BTB and CNC homology 1 (BACH1) target genes are involved in the oxidative stress response and in control of the cell cycle. Journal of Biological Chemistry. 2011;286:23521-32.

69. Moll L, Schubert M. The role of insulin and insulin-like growth factor-1/FoxO-mediated transcription for the pathogenesis of obesity-associated dementia. Current gerontology geriatrics research. 2012;2012.

70. Ostrowski PP, Barszczyk A, Forstenpointner J, Zheng W, Feng Z-P. Meta-analysis of serum insulin-like growth factor 1 in Alzheimer's disease. PloS one. 2016;11.

71. Gubbi S, Quipildor GF, Barzilai N, Huffman DM, Milman S. 40 YEARS of IGF1: IGF1: the Jekyll and Hyde of the aging brain. Journal of molecular endocrinology. 2018;61:T171-T85.

72. Freude S, Schilbach K, Schubert M. The role of IGF-1 receptor and insulin receptor signaling for the pathogenesis of Alzheimer's disease: from model organisms to human disease. Current Alzheimer Research. 2009;6:213-23.

73. George C, Gontier G, Lacube P, François J-C, Holzenberger M, Aïd S. The Alzheimer's disease transcriptome mimics the neuroprotective signature of IGF-1 receptor-deficient neurons. Brain. 2017;140:2012-27.

74. Galle SA, Van Der Spek A, Drent ML, Brugts MP, Scherder EJ, Janssen JA, et al. Revisiting the role of insulin-like growth factor-I receptor stimulating activity and the apolipoprotein $\mathrm{E}$ in Alzheimer's disease. Frontiers in aging neuroscience. 2019;11:20.

75. Tsuruzoe K, Emkey R, Kriauciunas KM, Ueki K, Kahn CR. Insulin receptor substrate 3 (IRS3 ) and IRS-4 impair IRS-1-and IRS-2-mediated signaling. Molecular \& cellular biology. 2001;21:26-38.

76. Jackson HM, Soto I, Graham LC, Carter GW, Howell GR. Clustering of transcriptional 
profiles identifies changes to insulin signaling as an early event in a mouse model of Alzheimer's disease. BMC genomics. 2013;14:831.

77. Cesarini V, Martini M, Vitiani LR, Gravina GL, Di Agostino S, Graziani G, et al. Type 5 phosphodiesterase regulates glioblastoma multiforme aggressiveness and clinical outcome. Oncotarget. 2017;8:13223-39.

78. Manso-Calderón R. Genetics in vascular dementia. Future Neurology. 2019;14:FNL5.

79. Wallace S, Guo DC, Regalado E, Mellor-Crummey L, Bamshad M, Nickerson DA, et al. Disrupted nitric oxide signaling due to GUCY1A3 mutations increases risk for moyamoya disease, achalasia and hypertension. Clinical genetics. 2016;90:351-60.

80. Palmieri O, Mazza T, Merla A, Fusilli C, Cuttitta A, Martino G, et al. Gene expression of muscular and neuronal pathways is cooperatively dysregulated in patients with idiopathic achalasia. Scientific Reports. 2016;6:31549.

81. Anderson KL, Ferreira A. $\alpha 1$ integrin activation: A link between $\beta$-amyloid deposition and neuronal death in aging hippocampal neurons. Journal of Neuroscience Research. 2004;75:688-97.

82. Li H, Zeng J, Huang L, Wu D, Liu L, Liu Y, et al. Microarray Analysis of Gene Expression Changes in Neuroplastin 65-Knockout Mice: Implications for Abnormal Cognition and Emotional Disorders. Neuroscience bulletin. 2018;34:779-88.

83. Kalman J, Kitajka K, Pakaski M, Zvara A, Juhasz A, Vincze G, et al. Gene expression profile analysis of lymphocytes from Alzheimer's patients. Psychiatric genetics. 2005;15:1-6.

84. Deiteren K, Hendriks D, Scharpé S, Lambeir AM. Carboxypeptidase M: multiple alliances and unknown partners. Clinica chimica acta. 2009;399:24-39.

85. Tang X, Li Z, Zhang W, Yao ZJNO. Nitric oxide might be an inducing factor in cognitive impairment in Alzheimer's disease via downregulating the monocarboxylate transporter 1. 2019.

86. Balez R, Ooi L. Getting to NO Alzheimer's disease: neuroprotection versus neurotoxicity mediated by nitric oxide. Oxidative Medicine and Cellular Longevity. 2016;2016.

87. Sarkar S, Korolchuk VI, Renna M, Imarisio S, Fleming A, Williams A, et al. Complex inhibitory effects of nitric oxide on autophagy. Molecular cell. 2011;43:19-32.

88. Morris G, Berk M, Maes M, Puri BK. Could Alzheimer's disease originate in the periphery and if so how so? Molecular neurobiology. 2019;56:406-34.

89. Uddin M, Stachowiak A, Mamun AA, Tzvetkov NT, Takeda S, Atanasov AG, et al. Autophagy and Alzheimer's disease: from molecular mechanisms to therapeutic implications. Frontiers in Aging Neuroscience. 2018;10:4.

90. Cheng Y, Cawley N, Yanik T, Murthy S, Liu C, Kasikci F, et al. A human carboxypeptidase E/NF- $\alpha 1$ gene mutation in an Alzheimer's disease patient leads to dementia and depression in mice. Translational psychiatry. 2016;6:e973-e.

91. Puzzo D, Loreto C, Giunta S, Musumeci G, Frasca G, Podda MV, et al. Effect of phosphodiesterase-5 inhibition on apoptosis and beta amyloid load in aged mice.

Neurobiology of Aging. 2014;35:520-31.

92. Kelleher RJ, Shen J. Presenilin-1 mutations and Alzheimer's disease. Proceedings of the National Academy of Sciences. 2017;114:629-31.

93. Paris D, Ait-Ghezala G, Bachmeier C, Laco G, Beaulieu-Abdelahad D, Lin Y, et al. The spleen tyrosine kinase (Syk) regulates Alzheimer amyloid- $\beta$ production and Tau 
hyperphosphorylation. Journal of Biological Chemistry. 2014;289:33927-44.

94. Schweig JE, Yao H, Beaulieu-Abdelahad D, Ait-Ghezala G, Mouzon B, Crawford F, et al. Alzheimer's disease pathological lesions activate the spleen tyrosine kinase. Acta Neuropathologica Communications. 2017;5:69.

95. Lemire BD. Evolution, structure and membrane association of NDUFAF6, an assembly factor for NADH: ubiquinone oxidoreductase (Complex I). Mitochondrion. 2017;35:13-22.

96. Bagwe-Parab S, Kaur G. Molecular targets and therapeutic interventions for Iron induced neurodegeneration. Brain Research Bulletin. 2019.

97. Kong W, Mou X, Liu Q, Chen Z, Vanderburg CR, Rogers JT, et al. Independent component analysis of Alzheimer's DNA microarray gene expression data. Molecular Neurodegeneration. 2009;4:5.

98. Kong W, Mou X, Hu X. Exploring matrix factorization techniques for significant genes identification of Alzheimer's disease microarray gene expression data. BMC bioinformatics. 2011;12 Suppl 5:S7.

99. Peng Y, Shapiro SL, Banduseela VC, Dieterich IA, Hewitt KJ, Bresnick EH, et al. Increased transport of acetyl-CoA into the endoplasmic reticulum causes a progeria-like phenotype. Aging cell. 2018;17:e12820-e.

100. Peng Y, Shapiro S, Hewitt K, Kong G, Bresnick E, Zhang J, et al. SYSTEMIC OVEREXPRESSION OF AT-1/SLC33A1 CAUSES A PROGERIA-LIKE PHENOTYPE. Innovation in Aging. 2017;1:426.

101. Huppke P, Brendel C, Kalscheuer V, Korenke GC, Marquardt I, Freisinger P, et al. Mutations in SLC33A1 cause a lethal autosomal-recessive disorder with congenital cataracts, hearing loss, and low serum copper and ceruloplasmin. The American Journal of Human Genetics. 2012;90:61-8.

102. Wang L, Yin Y-L, Liu X-Z, Shen P, Zheng Y-G, Lan X-R, et al. Current understanding of metal ions in the pathogenesis of Alzheimer's disease. Translational Neurodegeneration. 2020;9:1-13.

103. Sun LL, Yang SL, Sun H, Li WD, Duan SR. Molecular differences in Alzheimer's disease between male and female patients determined by integrative network analysis. Journal of Cellular and Molecular Medicine. 2019;23:47-58.

104. Podcasy JL, Epperson CN. Considering sex and gender in Alzheimer disease and other dementias. Dialogues in clinical neuroscience. 2016;18:437-46.

105. Sinforiani E, Citterio A, Zucchella C, Bono G, Corbetta S, Merlo P, et al. Impact of gender differences on the outcome of Alzheimer's disease. Dementia and geriatric cognitive disorders. 2010;30:147-54.

106. Devi G, Scheltens P. Heterogeneity of Alzheimer's disease: consequence for drug trials? Alzheimer's Research \& Therapy. 2018;10:1-3.

107. Au R, Piers RJ, Lancashire L. Back to the future: Alzheimer's disease heterogeneity revisited. Alzheimer's Dementia: Diagnosis, Assessment Disease Monitoring. 2015;1:368.

108. Ferreira D, Wahlund L-O, Westman E. The heterogeneity within Alzheimer's disease. Aging. 2018;10:3058. 